\title{
Modeling the economic costs of disasters and recovery: analysis using a dynamic computable general equilibrium model
}

\author{
W. Xie ${ }^{1,3}$, N. Li ${ }^{1,2,3}$, J.-D. Wu ${ }^{1,2,3}$, and X.-L. Hao ${ }^{1,3}$ \\ ${ }^{1}$ State Key Laboratory of Earth Surface Processes and Resource Ecology (Beijing Normal University), Beijing 100875, China \\ ${ }^{2}$ Key Laboratory of Environmental Change and Natural Disaster (Beijing Normal University), Ministry of Education, \\ Beijing 100875, China \\ ${ }^{3}$ Academy of Disaster Reduction and Emergency Management, Ministry of Civil Affairs \& Ministry of Education, \\ Beijing Normal University, Beijing 100875, China
}

Correspondence to: N. Li (ningli@bnu.edu.cn) and W. Xie (xiewei@mail.bnu.edu.cn)

Received: 5 July 2013 - Published in Nat. Hazards Earth Syst. Sci. Discuss.: 8 November 2013

Revised: 22 October 2013 - Accepted: 27 February 2014 - Published: 8 April 2014

\begin{abstract}
Disaster damages have negative effects on the economy, whereas reconstruction investment has positive effects. The aim of this study is to model economic causes of disasters and recovery involving the positive effects of reconstruction activities. Computable general equilibrium (CGE) model is a promising approach because it can incorporate these two kinds of shocks into a unified framework and furthermore avoid the double-counting problem. In order to factor both shocks into the CGE model, direct loss is set as the amount of capital stock reduced on the supply side of the economy; a portion of investments restores the capital stock in an existing period; an investment-driven dynamic model is formulated according to available reconstruction data, and the rest of a given country's saving is set as an endogenous variable to balance the fixed investment. The 2008 Wenchuan Earthquake is selected as a case study to illustrate the model, and three scenarios are constructed: $S_{0}$ (no disaster occurs), $S_{1}$ (disaster occurs with reconstruction investment) and $S_{2}$ (disaster occurs without reconstruction investment). $S_{0}$ is taken as business as usual, and the differences between $S_{1}$ and $S_{0}$ and that between $S_{2}$ and $S_{0}$ can be interpreted as economic losses including reconstruction and excluding reconstruction, respectively. The study showed that output from $S_{1}$ is found to be closer to real data than that from $S_{2}$. Economic loss under $\mathrm{S} 2$ is roughly 1.5 times that under $S_{1}$. The gap in the economic aggregate between $S_{1}$ and $S_{0}$ is reduced to $3 \%$ at the end of government-led reconstruction activity, a level that should take another four years to achieve under $S_{2}$.
\end{abstract}

\section{Introduction}

Natural disasters not only cause serious direct losses, such as house collapse or infrastructure damage, but also have strong impacts on the development of the macro economy, such as economic decline and unemployment (FEMA, 2011; Przyluski and Hallegatte, 2011). After every large-scale disaster, government institutions, insurance markets, and the media have primarily focused on the resulting direct losses but have hardly announced the economic impacts. However, during post-disaster reconstruction periods, the governments of various nations used to use economic indicators to define the goals of their recovery. For example, in the aftermath of the 2008 Wenchuan Earthquake, the Chinese government set the goal of pushing employment in every family and promoting economic development within approximately 3 years (NDRC, 2008). In the "Road to Recovery" report regarding the Great East Japan Earthquake, the Japanese government designated a 10-year period for reconstruction. The budget scale for the next 10 years is 23 trillion Japanese Yen (JPY) (the exchange rate of JPY to USD was 0.01157 in 2012), and the average real growth rate of the economy is expected to be approximately $2 \%$ (Government of Japan, 2012). After Hurricane Katrina in 2005, Louisiana faced a 766 percent increase in initial unemployment claims. The local government developed new industries or assisted their proven, dominant industries to recover its employment and stabilize its economic base within two years of the storm (Kates et al., 2006). Therefore, if scientists can assess the impact of 
disasters on economic indicators shortly following a disaster, governments would have a solid theoretical basis for developing reconstruction and recovery policies.

The economic costs of natural disasters are often measured by indicators such as value added, gross output, or employment status (ECLAC, 2003). The ways in which natural disasters affect economies are complex: after a disaster, the damage to plants and factory facilities leads to the suspension of operation or slashing of production, which are considered the direct impacts of disasters on the economy. The shortage of raw material and workers is another effect, and the disruption of industrial chains also induces production losses. Moreover, there also exists a chain effect among representatives of the economic system, such as unemployment resulting in low income, and terrible production activity resulting in low taxes, which are other impacts of disasters on the demand side of the economy. In addition, unlike the impact of social policy on an economic system, which is a concentrated sectoral event, the impact of natural disasters cuts a wide swath across a range of regional economic activities. Thus, when evaluating the impact of natural disasters, avoiding underestimates or overestimates resulting from double counting is a difficult task. Another matter that needs to be emphasized is the fact that disasters have negative impacts on the economy, while reconstruction and the related policy have positive impacts on the economy (IPCC, 2012), for example, government aid, paired-assistance policy, special finance policy, tax and fee preference, social donations, mutual help and assistance, etc. (Shi, 2012; Xie et al., 2012; Shi et al., 2013). Overall, if we could model the economic costs of disasters and recovery from all types of conduits and consider both the positive and negative effects when assessing the impacts, we would reach more objective conclusions and predict the trends of economic development under different reconstruction policies, which is beneficial for policy makers.

To date, there has been a great amount of research on the impact of natural disasters on the economy based on the input-output (I-O) model, econometric model and computable general equilibrium (CGE) model. These studies have made significant contributions in this respect but still require further improvement, i.e., the positive effects of reconstruction investment need to be incorporated into the assessment framework. For example, in the case of estimating the economic impact from damaged transportation systems due to disasters, freight transport and labor force may be reduced, which further affect the regional economy. However, the model did not take into account positive aspects, such as the increase in capital stock during reconstruction periods. Thus, the model only indicates the maximum potential losses due to natural disasters (Tirasirichai and Enke, 2007; Xie et al., 2012). Rose et al. (2007) evaluated the economic costs of an electricity blackout using the CGE model, incorporating the positive effects of resilience, including substitution, efficiency enhancement and price signals, but they did not model the reconstruction procedures that also exerted positive effects on the economy. Sue Wing (2010) performed an assessment of the economic cost of a storm scenario based on the dynamic CGE model, in which only positive impact from supply side is simulated while other important impact from demand side (such as a surge of demand for construction) is neglected. Hallegatte (2008) assessed the economic costs of the 2005 Hurricane Katrina disaster in America using the adaptive regional input output (ARIO) model, whose greatest advantage was that it could model the monthly changes in the economy after the disaster. In terms of the positive effects of reconstruction, this model incorporated a parameter called overproduction capacity (sectors can instantaneously produce $\alpha$ times more than the pre-disaster production level if demand increases. This overproduction capacity can also increase because additional equipment and workers can move to the affected region.), which was difficult to relate to the real aid that the government provided for reconstruction in the aftermath of the disaster, such as the tremendous investments, tax benefits, and technical support. Haimes et al. (2005a, b) and Jung et al. (2009) designed the inoperability input output (IIM) model, which was effective in assessing the impacts on the supply side of the economy, but it does not consider any positive effects of reconstruction activity. Moreover, Okuyama (2007), Tatano and Tsuchiya (2008), Santos et al. (2012), Wu et al. (2012) and Xie et al. (2012) have all assessed the economic costs of natural disasters based on regional economic models. Those previous studies made many contributions to analyzing how the disaster affected our economic system and investigating how to incorporate direct economic loss into the CGE or I-O models. However, most studies have focused on the negative impacts of disasters and have neglected or simplified positive impacts, or have used contextual assumptions to address positive impacts.

Economic resilience is a major way to reduce losses from disasters. Economic resilience can be classified as static economic resilience - the ability of an entity or system to maintain function (e.g., continue producing) when shocked - and dynamic resilience - the speed at which an entity or system recovers from a severe shock to achieve a desired state (Rose, 2007). The typical examples of static economic resilience are the use of inventories, backup generation, conservation, input substitution, and rescheduling of lost production. To date, most of the efforts to investigate static resilience pertain to measuring static economic resilience. Disaster-proof reconstruction in this article is an example of dynamic economic resilience. Meanwhile reconstruction will embody the latest technology, and there will be a productivity advance. Thus, this article puts forward several new examples of dynamic economic resilience and quantifies the positive effect of reconstruction. The second aim of this study was to assess the economic impacts of disasters incorporating the positive effects of reconstruction, and contributions of reconstruction actions (e.g., government aid, tax and fee prefer- 


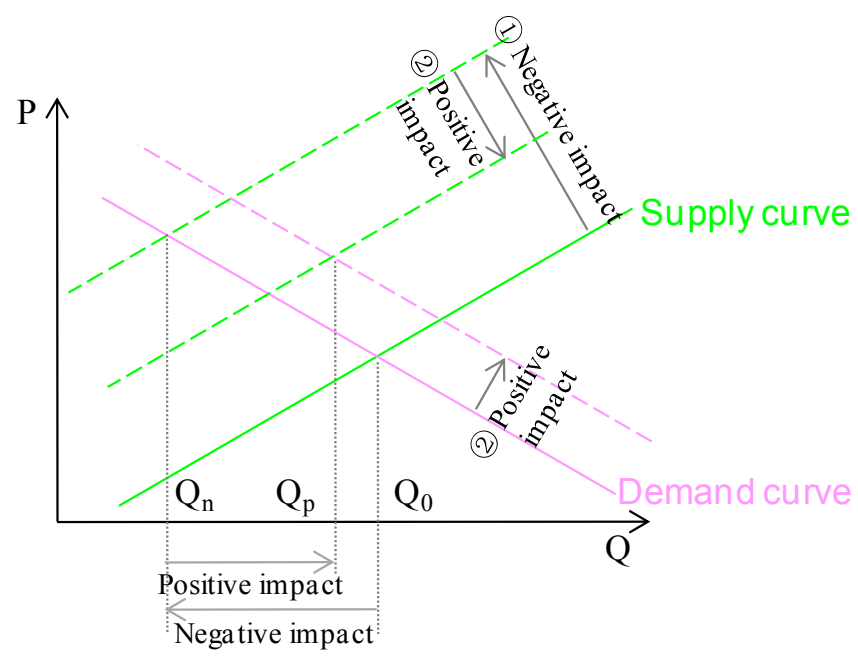

Fig. 1. The mechanism of negative impacts of disasters and positive impacts of disaster-proof reconstruction on the social economy.

ence, special finance policy, paired-assistance policy, social donations, mutual help and assistance) in a comprehensive manner. This article is organized into five sections. Section 2 discusses how the standard CGE model can be modified into a new model capable of simulating the negative effects of disasters and the positive effects of reconstruction activity after examining the mechanism and channels of positive and negative impacts induced by disasters. Section 3 is the introduction of the 2008 Wenchuan Earthquake in China, the ensuing reconstruction and the data needed. Section 4 constructs three scenarios: $S_{0}$ (no disaster occurs), $S_{1}$ (disaster occurs with reconstruction investment), and $S_{2}$ (disaster occurs without reconstruction investment) within the CGE model framework. $S_{0}$ is taken as a business as usual (BAU) scenario, and the difference between $S_{1}$ and $S_{0}$ and that between $S_{2}$ and $S_{0}$ are defined as economic loss including reconstruction and excluding reconstruction, respectively. The difference between the two types of losses is considered to be the contribution of reconstruction. Finally, Sect. 5 summarizes our findings and proposes directions for further research.

\section{A dynamic computable general equilibrium model}

\subsection{The mechanism of the impacts that natural disasters exerted on the social economy}

The impacts that earthquakes exert on economic activities are negative, while that impacts from disaster-proof reconstruction are positive (Fig. 1).

Regarding negative impacts, earthquakes lead to a decline in the population, manifested by large quantities of sudden deaths or injuries that reduce working ability, and a reduction in capital stock, manifested by the destruction of infrastruc- tures, machinery equipment and plants, causing a leftward shift of the aggregate supply curve and a slump in the supply capacity of the economy.

Regarding positive impacts, there are both demand- and supply-side shocks. From the perspective of the supply side, current reconstruction investments restore the capital stocks in the following periods, and damaged capital stocks are supplemented and recovered, leading to a rightward shift of the aggregate supply curve. From the perspective of the demand side, during the reconstruction period, to recover the capital stock of the economy and satisfy the need for normal investing activities, there will be great acceleration and a rise in the demand for investment in disaster areas. Meanwhile, disaster victims must decorate their newly built houses and purchase indoor facilities, which accelerates the recovery of consumption needs to some extent. Moreover, the government will pour necessary public funds into reconstruction. Altogether, the effects on consumption should be positive, resulting in a rightward shift of the aggregate demand curve. The two forces of supply and demand exert positive effects on the economy. Moreover, tax benefits also have a great positive effect on the economy.

The CGE model can simulate both the positive and negative impacts within a unified framework and thus avoid the underestimation, overestimation or double-counting problem of economic losses. Also, CGE models provide an ex ante simulation laboratory for conducting counterfactual analysis. This allows us to establish different scenarios. Ex post methods are able to make assessments within real contexts, but the assessment of the losses caused by a disaster requires a comparison of the discrepancies between two different scenarios. Thus the CGE model is one of the most employed modeling approaches in the literature to account for the effects of natural disasters on the economy (Wittwer and Griffith, 2011; Horridge et al., 2005; Greenberg et al., 2007, 2012; Pauw et al., 2011). For example, the CGE model has been widely used in the evaluation of the impacts of water or electricity disruption on the economy (Rose and Liao, 2005; Rose et al., 2007). Moreover, during post-disaster periods, the investment in the current year restores capital stock in the next year. It means that there is a link among every year after a disaster. Therefore, to assess the negative impacts of reduced capital stock and the positive impact of post-disaster reconstruction based on the CGE model, it is necessary to develop the static CGE model into a dynamic CGE model.

\subsection{Improvement of the traditional CGE model}

The traditional dynamic CGE model is suggested to refer to the Appendix. Our CGE model belongs to a family of CGE models maintained at the Development Research Center of the State Council in China. The following parts mainly introduce our improvement of the traditional dynamic CGE model to simulate negative disaster shocks and the positive effects of reconstruction within a unified framework. 


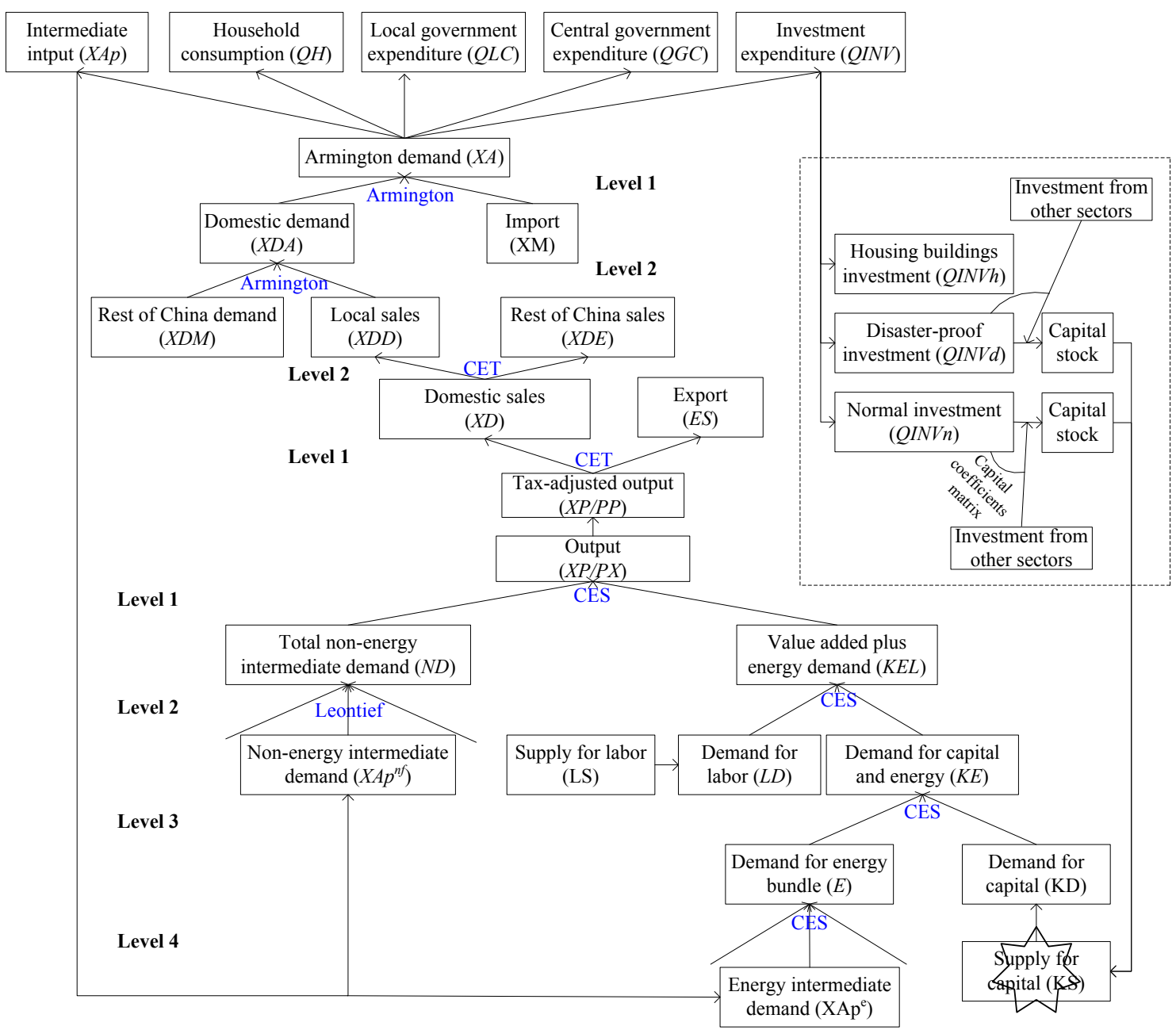

Fig. 2. The framework of the CGE model, which reflects reconstruction following a disaster (non-dotted line box: the traditional CGE model; dotted line box: the reflection of the disaster shocks and the reconstruction following a disaster).

Some improvements that reflect disaster shocks and reconstruction investment are indicated by the dotted line box in Fig. 2. Specifically, during post-disaster reconstruction, governments provide some benefits regarding the production tax. Tax benefits are achieved by reducing the tpc and tpr parameter values in the traditional CGE model. Other major improvements include the market clearing block, macro-closure block and dynamic block.

\subsubsection{Improvement of market clearing}

Equation (A11) in the Appendix for traditional market clearing and macro-closure block is improved with Eq. (1). Firstly, total investment is divided into normal investment and reconstruction investment. Secondly, direct loss from damaged houses is the main component of total direct loss; thus, house investment accounts for a relatively large proportion of the total reconstruction investment. Nevertheless, the capital stock formed from house investment hardly con- tributes to expanded production in the next period (Hallegatte, 2008). Thus, house investment mainly exerts a positive impact on the demand side of the economy. Accordingly, reconstruction investment is further divided into house investment and other reconstruction investments.

$$
\begin{aligned}
\mathrm{XA}_{i}= & \overbrace{\sum_{j} \mathrm{XAp}_{i, j}+\mathrm{QH}_{i}+\mathrm{QLC}_{i}+\mathrm{QGC}_{i}+\mathrm{QINVn}_{i}}^{\text {Local normal demand }} \\
& +\overbrace{\mathrm{QINVh}_{i}+\sum_{j} \mathrm{QINVd}_{i, j}}^{\text {Disaster-proof demand }},
\end{aligned}
$$

where we divided the total investments into normal investments (QINVn), disaster-proof investments (QINVd), and house investments (QINVh). The meanings of other variables are explained in Fig. 2. 
Traditional CGE models close the labor market under either the "Neoclassical" assumption of full employment (perfectly inelastic supply) or the "Keynesian" assumption of variable employment (perfectly elastic supply at a fixed wage). Disasters have significant effects on both labor supply and wage rates. However, the standard closure rules hold one of these constant (Sue Wing, 2010). Thus, in our model, labor flows among different sectors through the use of constant elasticity of transformation (CET) functions. Accordingly, we model labor as a variable factor whose endowment is price-responsive, which is achieved by specifying a shortrun labor supply curve with elasticity $\omega^{L}$, which scales the labor supply from its benchmark level (Eq. 2). Moreover, all industries suffer stock losses greatly from a catastrophe, then they all increase investments in the reconstruction period. To incorporate this special aftermath into the model, sector-specific capital is assumed within a short time in our model.

$\mathrm{LS}=\overline{\mathrm{LS}} * W^{\omega_{\mathrm{L}}}$

where LS indicates the labor supply, $\overline{\mathrm{LS}}$ indicates the labor supply in a base period, $W$ is salary and $\omega_{\mathrm{L}}$ indicates the price elasticity of the labor supply.

\subsubsection{Improvement of macro-closure rules}

The investment amount in each industry is exogenous, and the total amount saved is determined by the total investment endogenously. Specifically, the model has a fixed savings rate for the afflicted region and allows savings inflows from other regions to balance the equation. This improvement of macroclosure can reflect collection of reconstruction funds from the rest of the country, e.g., the central government, other provincial governments, enterprises and residents. The exchange rate is endogenous, and foreign savings are exogenous.

\subsubsection{Improvement of the dynamic module}

The total investments, excluding reconstruction investments, are roughly counted as normal investments. In this model, normal investments are distributed among various industries based on the industry investment structure in the base year, and then transformed into the capital stock (XCn) in the following period according to the investment coefficient matrix (Eq. 3) (Miller and Blair, 1985). The disaster-proof investments can also be transformed into capital stock (XCd), and the distribution of transformed capital stocks among industries is determined by the proportion of the direct losses suffered by those industries; then the disaster-proof investments of various industries can be achieved according to the investment coefficient matrix (Eq. 4).

The model presumes that there is a housing sector. The damage to the housing inventory will bring newly increased investments but no contribution to the capital stock of other industries. In each period, the housing capital stock ( $\mathrm{XCh})$ is calculated by multiplying the total investments in that period by the ratio of direct losses in the housing sector accounting for total direct losses. Then, according to the investment coefficient matrix, the housing capital stock $(\mathrm{XCh})$ can be converted into the investments of various industries (Eq. 5).

$\mathrm{XCn}_{i}=B_{i, j}^{-1} \mathrm{QINVn}_{i}$

$\mathrm{XCd}_{i}=B_{i, j}^{-1} \sum_{j} \operatorname{QINVd}_{i, j}$

$\mathrm{XCh}=B_{h, j}^{-1} \mathrm{QINVh}_{i}$

Only in the year that the disaster occurred did natural disasters cause a decline in capital stock in various industries (damage). Considering the actual circumstances of reconstruction in China, to accelerate the process, most of the damaged floating assets, such as excavators used in the architecture industry, were imported from other areas, instead of waiting for local production. It means that the speed of investment restoring capital stock under post-disaster reconstruction circumstances is quicker than that under normal circumstances. In order to estimate this offsetting factor of reconstruction, in CGE mode a portion of the total investment is assumed to form capital stock in the first year, and the remaining portion will restore stock in the next year (Eq. 6).

$$
\begin{aligned}
\mathrm{KStock}_{i} & =\left(1-\delta_{i}\right)\left(\mathrm{KStock}_{i,-1}-\text { Damage }_{i,-1}+\text { Transfer }_{i,-1}\right) \\
& +\mathrm{XCn}_{i,-1}+\mathrm{XCd}_{i,-1}
\end{aligned}
$$

\section{Case introduction and data needed}

\subsection{Introduction to the earthquake}

The Wenchuan Earthquake occurred on May 12, 2008, with the epicenter located at Yingxiu Town, Wenchuan County, Sichuan Province of China $\left(31.01^{\circ} \mathrm{N}-103.40^{\circ} \mathrm{E}\right)$. The earthquake had a magnitude of Ms 8.0 (earthquake magnitude is usually measured on the popular Ms scale, which ranges from 0 to 10; an Ms 8.0 earthquake can destroy an area measuring 100 square miles) and a maximum intensity of $11^{\circ}$. It was the most destructive and widespread earthquake since the founding of the P.R.C., with 69226 dead and 17923 missing. The economic cost reached approximately 845.2 billion Chinese Yuan (CNY) (the exchange rate of CNY to USD was 0.14 in 2008), $91.3 \%$ of which represented the direct economic losses of Sichuan Province, which were equivalent to $74 \%$ of its GDP (Gross Domestic Product) in 2007. For the direct economic losses of specific industries, please refer to Table 1 (NCDR, 2008). There were 10 counties covering 
Table 1. Direct economic loss due to the Wenchuan Earthquake distributed by sectors in Sichuan (Unit CNY 100 million).

\begin{tabular}{lll}
\hline ID & Sector & Loss \\
\hline 1 & Agriculture & 120 \\
2 & Mining industry & 100 \\
3 & Food manufacturing & 180 \\
4 & Textile, sewing machine and leather manufacturing & 45 \\
5 & Wood processing and furniture manufacturing & 45 \\
6 & Coke, gas and oil processing & 6 \\
7 & Chemical industry & 125 \\
8 & Construction material and other nonmetallic mineral manufacturing & 54 \\
9 & Metallic products manufacturing & 130 \\
10 & Mechanical equipment manufacturing & 220 \\
11 & Electricity, steam, hot-water production and supply & 800 \\
12 & Building trade & 25 \\
13 & Transportation, post and telecommunications & 840 \\
14 & Commerce and catering & 90 \\
15 & Finance and insurance & 1100 \\
16 & Specific service management & 60 \\
17 & Public utility and resident service & 550 \\
18 & Room service & 3000 \\
\hline
\end{tabular}

an area of $26400 \mathrm{~km}^{2}$ that were labeled as extremely damaged areas and 26 counties covering $61500 \mathrm{~km}^{2}$ that were labeled as seriously damaged areas. These counties accounted for $20 \%$ of the total 181 counties, and the total area represented $18 \%$ of the total $485000 \mathrm{~km}^{2}$ of Sichuan Province (NCDR, 2008; Sichuan Bureau of Statistics, 2012). In 2006 and 2007, before the earthquake, the GDP of those disaster areas accounted for $26 \%$ of the total GDP of Sichuan Province (Sichuan Bureau of Statistics, 2012).

\subsection{Introduction to post-earthquake reconstruction}

The government implemented many active policies to accelerate reconstruction and to mitigate the effects of the Wenchuan Earthquake. In September 2008, 4 months after the earthquake, the government introduced a plan called "The State Overall Plan for Post-Wenchuan Earthquake Restoration and Reconstruction" to accelerate the reconstruction process. The government also implemented active fiscal policies: central finance established reconstruction funds for post-quake reconstruction (approximately CNY 300 billion, i.e., $30 \%$ of the total direct losses), and these funds will be released over the 3 years following the earthquake. The local government of Sichuan also established comparable funds. These funds were collected through various channels: local government allocation, counterpart assistance, social donations, domestic bank loans, foreign emergency loans on favorable terms, urban and rural self-possessed and selfcollected capital, etc. In addition, 18 assistance provinces (cities) offered assistance with no less than $1 \%$ of their last ordinary budget revenues to their 18 counterpart counties (or districts) in Sichuan, respectively. Moreover, the government provided various preferential policies for local enter- prises and investors. These policies included alleviating the tax burden on individuals, deducting partial administrative charges, supporting key enterprises and medium- and smallsized enterprises, and adjusting industry entrance permission (NDRC, 2008). These preferential policies eased the burden on local reconstruction and accelerated reconstruction to some degree. For more detailed data regarding reconstruction investments, please refer to Table 2 (Sichuan Bureau of Statistics, 2012), where "-" indicates that the data for that year are unavailable.

\subsection{Data needed}

The model implemented in this study contains 17 sectors: 1 agricultural sector, 10 manufacturing sectors, 1 architecture sector and 5 service sectors; the merger of the sectors is based on the industry classification of available direct loss data. A substantial amount of the data processed by the model was obtained from the detailed 2007 Social Accounting Matrix (SAM) for Sichuan Province, derived from the SAM database compiled by the Development Research Center of the State Council (DRC-SAM) (DRC, 2000), which is the most widely used database for generating SAMs in China. In the CGE model, some elasticity parameters must be derived from the literature. These include the elasticities of transformation between export and domestic production and, in the second nest, between in-province and out-of-province production, as well as the elasticities in the Armington functions of the import block and elasticities in the CES functions of the production block. These parameters are based on a synthesis of the literature (Oladosu, 2000; Rose et al, 2007; Vennemo et al., 2009), and other major parameters were specified during the model calibration process. 
Table 2. Reconstruction investments supported by government over the $3 \mathrm{yr}$ after the earthquake (unit CNY 100 million).

\begin{tabular}{llllll}
\hline Year & & 2008 & 2009 & 2010 & Sum \\
\hline Reconstruction investments & Central government & 498.93 & 1085.98 & 618.52 & 2203.43 \\
& Provincial finance & - & $177.46^{\mathrm{a}}$ & 55.52 & $232.98^{\mathrm{b}}$ \\
& Counterpart assistance & - & - & - & 843.80 \\
& Donations & - & - & - & $760.22^{\mathrm{c}}$ \\
& Insurance & - & - & - & 16.60 \\
\hline
\end{tabular}

${ }^{a}$ It is an accumulation of 2008 and 2009. ${ }^{b}$ Only Sichuan Province. ${ }^{c}$ Among them, the special party dues amount to CNY 9.73 billion, other donations amount to CNY 55.582 billion, and the material depreciation cost is CNY 10.71 billion, and most of them are included in the government allocation.

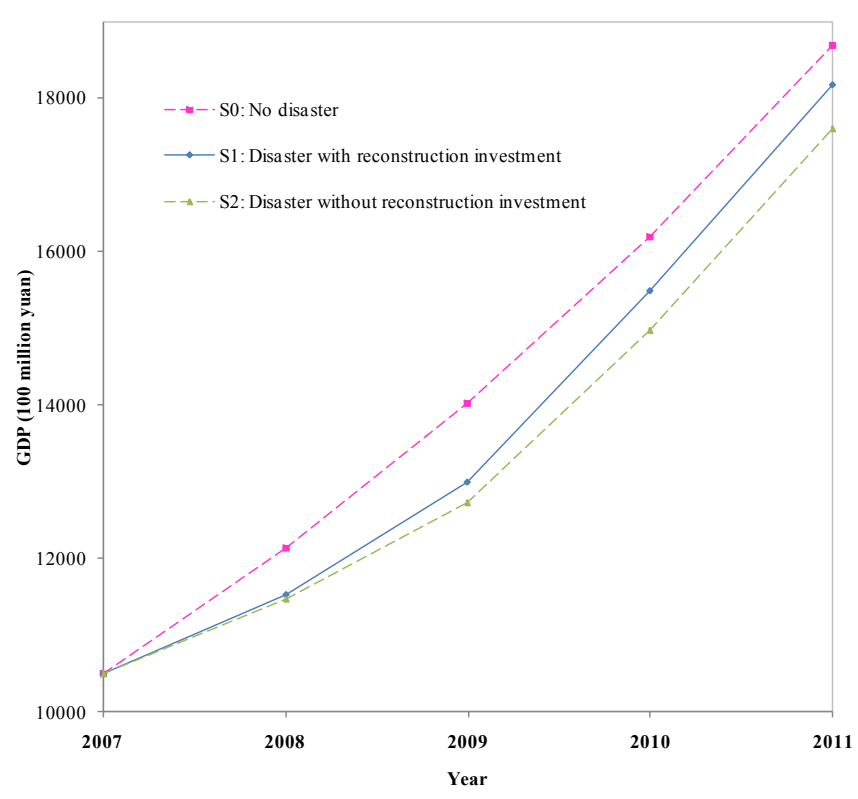

Fig. 3. GRP of Sichuan Province from 2007 to 2011 in three scenarios according to the CGE model.

Using the traditional CGE model, a dynamic block was incorporated into this study. Capital stocks in the benchmark year were estimated using a standard perpetual inventory approach (Goldsmith, 1951; Christensen and Jorgenson, 1973). The investment data from 2007 to 2011 were obtained from the Statistical Yearbook of Sichuan Province, and the investment data after 2011 were estimated depending on the average investment amount from 2003 to 2007 . Reconstruction investments were made only from 2008 to 2010 (please refer to Sect. 2.2). The average rates of depreciation of sectors and capital coefficients matrix were derived from authoritative reports or literature in China (Liao and Ma, 2009; Zhang et al., 2004).

The impacts of a disaster on the economy can be reflected by adjusting the exogenous variables Damage ${ }_{i, t}$ in the CGE model. Meanwhile, the impacts of the ensuing reconstruction can be reflected by adjusting the exogenous variables $\mathrm{QINVd}_{i, j}$ and $\mathrm{QINVh}_{i}$. Then, the economic system can achieve a new equilibrium. With the help of GAMS software, the CGE model can calculate a set of prices and quantities in a new equilibrium after a series of iteration operations. By comparing the two prices and quantities, we can assess the impacts of the disaster and the ensuing reconstruction on the economy.

\section{Simulation result}

\subsection{Three scenario}

In a rapidly growing economy such as China, the amount of post-disaster new investment (even excluding reconstruction investment) is often large compared with the amount of capital stock destroyed by the disaster, so the social and economic aggregate levels in the year when the disaster occurred may still surpass the pre-disaster level. In other words, a higher economic level compared with pre-disaster status does not mean that social and economic conditions are recovered. As a result, when assessing economic loss induced by disaster, it is wise to choose the no-disaster scenario as a benchmark. Though it is a counterfactual simulation, the dynamic CGE model used in this study can assess social and economic conditions under this scenario. Three scenarios were constructed in this study (Table 3): a non-disaster scenario in which capital stock was not reduced and there was only normal investment but not reconstruction investment $\left(S_{0}\right)$; a disaster scenario with reconstruction investment, in which the capital stock is reduced due to disaster and there is normal investment and reconstruction investment, including housing and other investment $\left(S_{1}\right)$; and a disaster scenario without reconstruction in which the capital stock is reduced due to disaster and there is normal investment but not reconstruction investment $\left(S_{2}\right)$. $S_{0}$ was taken as a business as usual (BAU) scenario, and the differences between $S_{1}$ and $S_{0}$ and that between $S_{2}$ and $S_{0}$ can be interpreted as economic losses including reconstruction and excluding reconstruction, respectively. The difference between the two types of losses is then defined as the contribution of reconstruction. 
Table 3. Description of scenarios.

\begin{tabular}{ll}
\hline Scenario & Description \\
\hline$S_{0}$ (no disaster occurs) & \\
- & Annual GDP growth rate from 2008 to 2011 in Sichuan Province is \\
& set to $15.5 \%$ (i.e., GDP is an exogenous variable), according to the \\
& growth rate of those provinces whose economic development level \\
& is similar to that of Sichuan Province; \\
- & TFP (total factor productivity) is set as an endogenous variable; \\
- & There is only normal investment whose distribution among different \\
& sectors maintains its 2007 level.
\end{tabular}

$S_{1}$ (disaster occurs with reconstruction investment)

$S_{2}$ (disaster occurs without reconstruction investment)
- The disaster reduced capital stock. Because the disaster occurred in June 2008, the reduced amount is assumed to be half of the direct loss. Since 2009, the reduced amount of capital stock has been calculated according to aggregate direct loss;

- TFP is set as an exogenous variable, and its value is set based on $S_{0}$;

- There is normal investment and reconstruction investment. The distribution of normal investment among different sectors maintains its 2007 level. Reconstruction investment, except for that spent on housing, goes to different sectors with reference to the distribution of direct loss among sectors;

- Three years of tax preference (2008-2011);

- In 2008, half of the investment formed capital stock, reflecting quick recovery under the national disaster relief mechanism. The other half of the investment is transformed into capital stock based on the investment coefficient matrix in the next year.

- The disaster reduced capital stock;

- TFP is set as an exogenous variable;

- There is only normal investment but no reconstruction investment.

\subsection{The trend of economic development in three different scenarios}

The GDP before and after the Sichuan Earthquake disaster (2007-2011) in the three scenarios is shown in Fig. 3. The disaster occurred in 2008, and the government-led reconstruction investment occurred over the period 2008-2010. Figure 3 shows that reconstruction investment moves the GDP $\left(S_{1}\right)$ closer to the baseline scenario of no disaster $\left(S_{0}\right)$, but if there is no investment, the GDP $\left(S_{2}\right)$ would be much lower than the baseline scenario of no disaster $\left(S_{0}\right)$. Thus, the disaster economic assessment methods that do not involve the positive effects of reconstruction under-estimated the trajectory of post-disaster economy. In 2008, the year of the disaster, major efforts were made in post-disaster emergency rescue, reconstruction planning, etc. Meanwhile, reconstruction work advanced slowly and only part of the reconstruction investment was used to aid damaged plants, equipment and infrastructure. Moreover, the sudden occurrence of the disaster went against the planned government expenditure, and government investment in that year was lower compared to investments made in the following years. Thus, in 2008, the GDP values under the reconstruction scenarios $\left(S_{1}\right)$ and non-reconstruction scenarios $\left(S_{2}\right)$ are not very different. After 2009, with a large amount of reconstruction work to start and due to the rapid reconstruction of the whole country, part of the investment in that year will be able to be dedicated to plants, equipment, etc., so that industry recovers its production capacity. In the meantime, the government has obviously been increasing investment to reach a GDP $\left(S_{1}\right)$ that is close to that under the no-disaster scenario, especially in the years 2010 and 2011. Under the no-reconstruction scenario $\left(S_{2}\right)$, normal improved productivity (i.e., TFP in the CGE model) exists. On the other hand, there is ordinary investment under this scenario. Therefore, the economic level under $S_{2}$ 


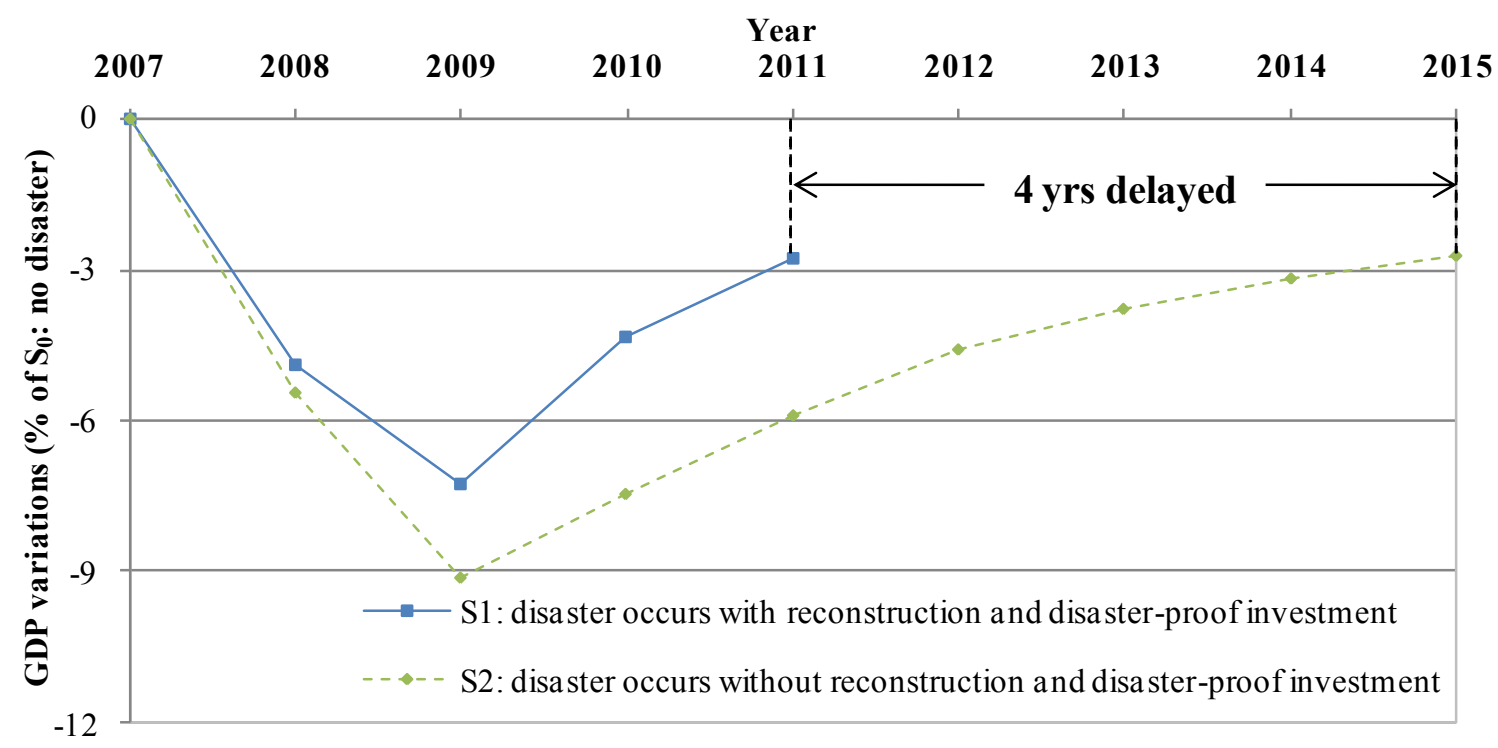

Fig. 4. Comparison of post-disaster economic recovery between $S_{1}$ and $S_{2}$.

also increases with time. However, due to damaged capital stock and unavailability of reconstruction activity, economic growth under $S_{2}$ is far lower than that in the no-disaster scenario. Therefore, rapid reconstruction work, making investments forming capital stock to supplement disaster-damaged plants, equipment, etc., and raising as many funds as possible for reconstruction by the government and market are effective channels for reducing economic losses.

It is believed that differences in GDP between the reconstruction scenario $\left(S_{1}\right)$ and no-disaster scenario $\left(S_{0}\right)$ are disaster losses, and that between the no-reconstruction scenario $\left(S_{2}\right)$ and no-disaster scenario $\left(S_{0}\right)$ are economic losses. Generally, over the period spanning from 2008 to 2011, under the reconstruction scenario $\left(S_{1}\right)$, the toll of GDP loss in Sichuan Province amounted 283.56 billion Yuan (the GDP loss rate is $4.0 \%$ ), and the average annual loss was 70.89 billion Yuan, accounting for $10 \%$ of direct economic losses. Under the no-reconstruction scenario $\left(S_{2}\right)$, the toll of GDP loss in Sichuan Province was 425.00 billion Yuan (the GDP loss rate is $5.9 \%$ ), with an average annual loss of 106.25 billion Yuan, accounting for $15 \%$ of direct economic losses. It can be seen that disaster economic loss assessment methods that do not involve reconstruction in the wake of the Wenchuan Earthquake will overestimate the GDP loss by approximately 1.5 times that under $S_{1}$.

\subsection{Recovery period}

In Fig. 4, GDP variations are measured on the ordinate axis to illustrate the economic recovery under the reconstruction scenario $\left(S_{1}\right)$ and no-reconstruction scenario $\left(S_{2}\right)$. Under the reconstruction scenario $\left(S_{1}\right)$, compared with that in 2006, the economic growth rate in 2007 was $14.2 \%$; compared with that in 2007, the economic growth rate in 2008 was $9.5 \%$; and compared with that in 2008 , the economic growth rate in 2009 was $14.5 \%$. It appears that the economic loss in the year of the earthquake was the greatest. Figure 4, however, shows that regardless of reconstruction scenario $\left(S_{1}\right)$ or noreconstruction scenario $\left(S_{2}\right)$, the GDP loss in 2009 was the greatest when the no-disaster scenario is set as the business as usual scenario. The reason is that on one hand the reconstruction work performed in 2008 advanced slowly. Meanwhile, major reconstruction efforts were focused on emergency relief and reconstruction planning. So, the damage amount of capital stock in 2008 was much the same as that in 2009. On the other hand, the destruction of plants, equipment and infrastructure by the Wenchuan Earthquake, which hit China on 12 May 2008, only affected about six months of the economic period in 2008. The earthquake's effects on the economy spread throughout the year of 2009. Therefore, the economic loss in 2009 was the greatest when the no-disaster scenario is set as the business as usual scenario.

The Chinese government aimed to provide funding and technological support to Sichuan Province for three years (from 2008 to 2010) in its Plan of Post-Disaster Restoration and Reconstruction after the Wenchuan Earthquake. We selected 2011 as the end of the restoration and reconstruction period in Sichuan because the investment in 2010 was vital to economic performance in 2011. Figure 4 shows that the difference in GDP in Sichuan in 2011 between the reconstruction scenario $\left(S_{1}\right)$ and the no-disaster scenario $\left(S_{0}\right)$ is less than 3\%. The GDP of Sichuan will not reach that level again until 2015 if the government does not support restoration and reconstruction $\left(S_{2}\right)$. Thus, it is concluded that reconstruction investment shortened the economic restoration period following the Wenchuan Earthquake by approximately 4 years. 


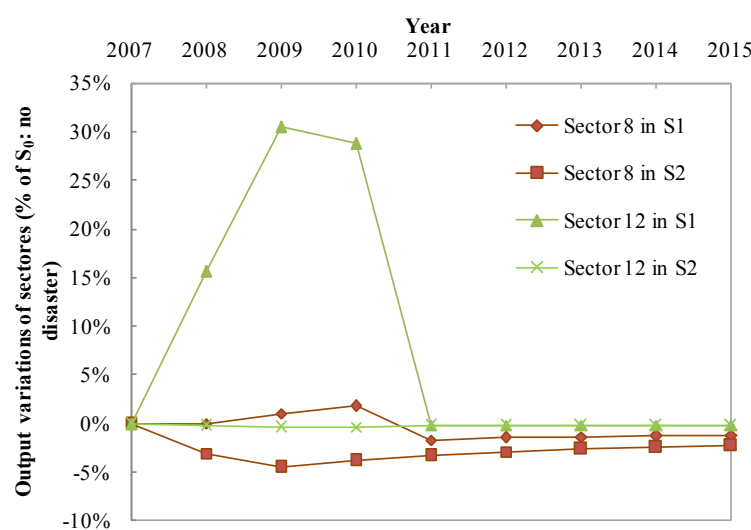

(a)

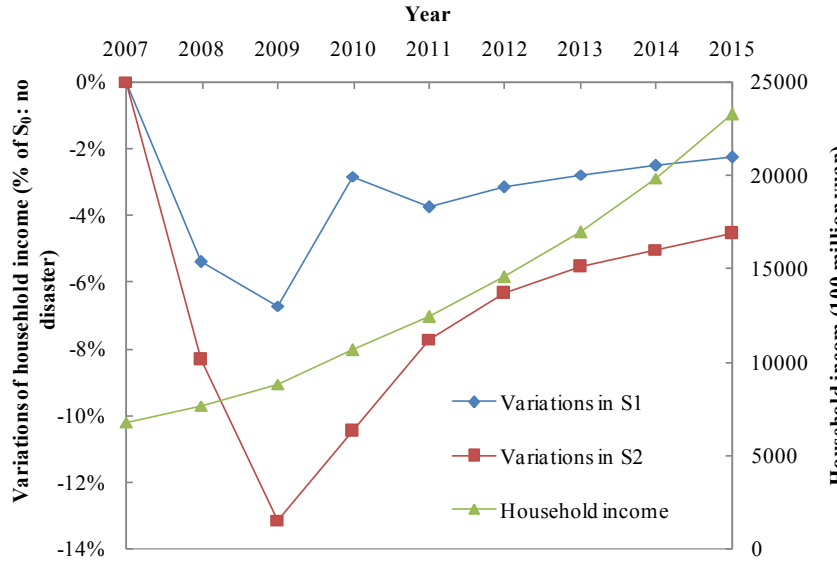

(c)

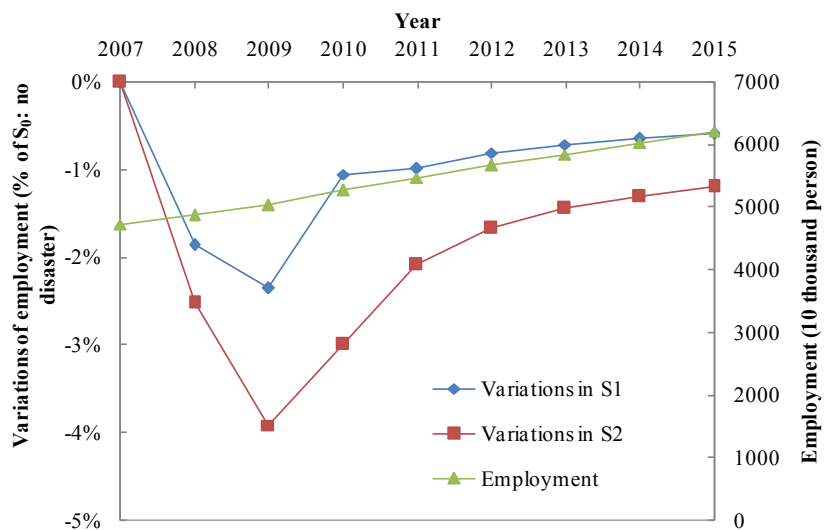

(b)

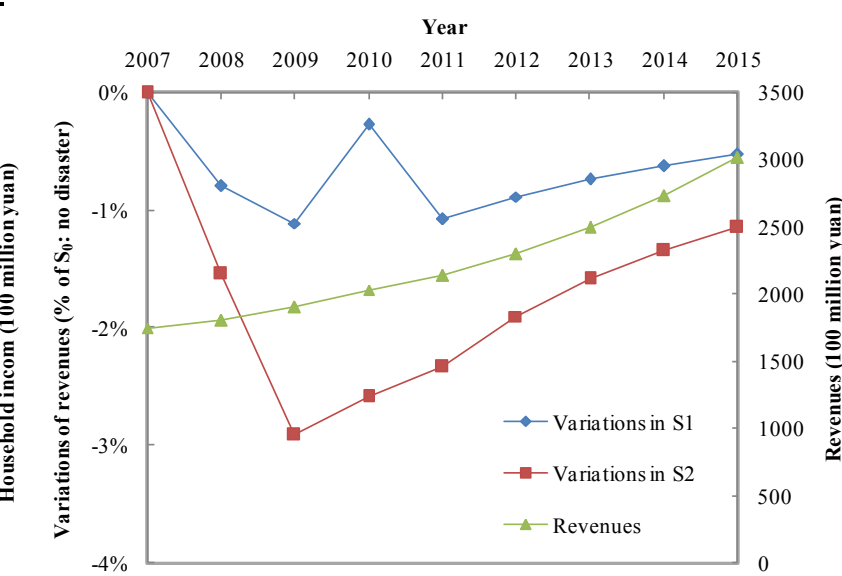

(d)

Fig. 5. The recovery process of post-disaster economic systems under different scenarios.

\subsection{Economic impacts of natural disasters}

The above comparison of recovery periods shows that the no-reconstruction scenario $\left(S_{2}\right)$ will not catch up with the reconstruction scenario $\left(S_{1}\right)$ until 2015. Therefore, the year 2015 was selected as an end point to analyze four indicators on which the government usually focuses, namely, sector effects, employment status, residents' income and government's revenue under two different scenarios (SCIO, 2011).

\subsubsection{Sector effects}

Compared with econometric models, the CGE model can not only demonstrate the change in aggregate economic quantities, but also the loss and restoration states of different industrial sectors in an economic system. According to the CGE model, all 17 industries suffered loss in scenario $S_{2}$, whereas in scenario $S_{1}$ because reconstruction demands more products and services from the construction and building material industries. Thus, from 2008 to 2010, the output of these two industries increased by $25 \%$ and $1 \%$, respectively, compared with those in the $S_{0}$ scenario (see Fig. 5a). The reason why there is such a huge disparity between increased production of the construction and building material industries may be that most reconstruction activities need the participation of the construction industry, but not every reconstruction activity needs building materials, such as cleaning debris or site performance for new buildings. Overall, in terms of the entire industrial sector, reconstruction will alleviate economic losses.

\subsubsection{Employment status}

Although employment is increasing gradually every year under $S_{1}$, the unemployment rate still exists, in contrast to the non-disaster scenario $\left(S_{0}\right)$ (see Fig. 5 b). The reduction in output from 15 of the 17 industries will lead to unemployment, which is why all governments focus on employment after disasters. However, the construction and building material industries need a greater labor force due to growing outputs driven by reconstruction. After every earthquake, the building industry observes rising wages but labor shortages. Following the Wenchuan Earthquake, labor inputs have been provided by other provinces and the return of local labor has supported reconstruction. Thus, reconstruction will promote employment, unlike under the non-reconstruction scenario. 


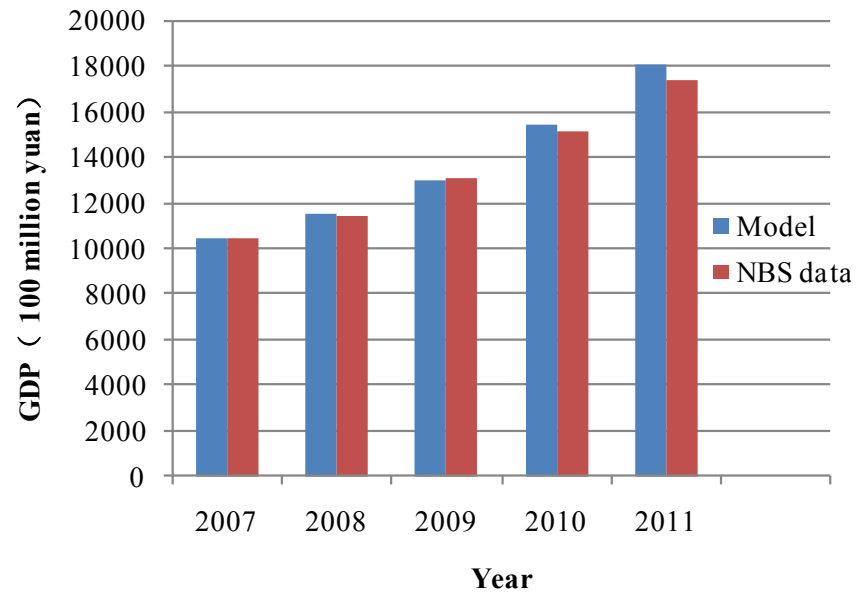

Fig. 6. GDP of Sichuan Province from 2007 to 2011 according to NBS data and scenario $S_{1}$ of the CGE model.

More than 2 million workers will recover their jobs from 2008 to 2011, averaging 5 million people annually, due to reconstruction.

\subsubsection{Residents' income}

Compared with IO models, CGE models not only depict the interaction among industries but also the changes in the income and spending of residents, companies and governments, etc. Under the $S_{1}$ scenario, residents' income has gained a steady increase, but compared with the no-disaster scenario, the income loss rate was the highest in 2009 (the reason is the same as that explaining why the highest GDP loss rate was observed in 2009). With continuing reconstruction, the loss rate began to decrease, except minor disturbance when reconstruction was finished at the end of 2010. Later, with the gradual recovery of the economy, residents' income returned to the no-disaster level (see Fig. 5c). Overall, reconstruction enhanced employment and further increased residents' income. From 2008 to 2010, the income loss rates under the $S_{1}$ and $S_{2}$ scenarios were $5 \%$ and $10 \%$, respectively.

\subsubsection{The fiscal revenue of Sichuan Province}

Under the $S_{1}$ scenario, the fiscal revenue of the local government maintained a small increase each year; nevertheless, compared with the no-disaster scenario, there were some losses and the loss rate reached its lowest level in 2010, when the reconstruction guided by the government was terminated. Then, with the gradual recovery of the economy, the fiscal revenue of the local government recovered to the no-disaster level (see Fig. 5d). Fortunately, compared with the $S_{2}$ scenario, reconstruction promoted the total output of all industries further as well as the fiscal revenue of the local government. From 2008 to 2010, the loss rate of the fiscal revenue of the local government under $S_{1}$ was less than $1 \%$, whereas the rate under $S_{2}$ was more than $2 \%$. To summarize, reconstruction exerts positive effects on economic development; hence, the assessment of economic losses sustained after disasters must consider the positive effects of reconstruction.

\subsection{Model test}

The CGE model implemented in this study used reconstruction data published by the government, such as reconstruction investment, tax preference, donation and paired assistance, as model inputs. The model does not require data processing, so that evaluation results are much more objective. In fact, the reconstruction scenario $\left(S_{1}\right)$ is the same as a real situation after a disaster. In Fig. 6, to test the accuracy of the model, GDP under the reconstruction scenario $\left(S_{1}\right)$ is compared with GDP published by NBS. As indicated, the model and NBS data are quite similar from 2007 to 2011. The differences in certain years may be attributed to the fact that during the simulation period, the distribution of normal investment in different sectors was assumed to be roughly the same as that observed in 2007. However, there may be some differences in reality, and more detailed investment data classified by sectors at the provincial level were unavailable.

The reliability of the model results can be verified from another perspective. Sichuan Province was divided into extremely hard-hit areas, hard-hit areas and the rest of Sichuan, whose post-disaster GDP trends from 2007 to 2011 (solid line in Fig. 7) were then analyzed. In Fig. 7, a decreasing trend for GDP was observed in extremely hard-hit areas between 2008 and 2010. Thus, extremely hard-hit areas lost a three-year opportunity for economic growth. A similar situation was faced by hard-hit areas, which experienced a moderate decrease in GDP in 2008 and a minor increase in GDP in 2009. Hard-hit areas also missed an opportunity for economic growth. Conversely, GDP in the rest of Sichuan and Sichuan Province showed a growth trend. If the GDP growth rate in extremely hard-hit areas and hard-hit areas is assumed to be the same as that of the rest of Sichuan (the dotted line in Fig. 7c), the GDP under the non-disaster scenario in Sichuan can be estimated (the dotted line in Fig. 7d). As a result, the difference between the solid line available from NBS and the dotted line at the bottom right of Fig. 7 embodies the GDP loss rate, i.e., $5.2 \%$ in 5 years total. According to the published literature (Okuyama, 2004), the post-disaster GDP growth rate of the unaffected areas in Sichuan should be accelerated due to their role in supplying raw material to affected areas. Thus, this simple method overestimated the GDP loss. The dynamic CGE model in this study assessed the GDP loss rate as $4.0 \%$, just slightly lower than the results of the above simple method. Therefore, there is reliability about the dynamic CGE model applied in this study. 


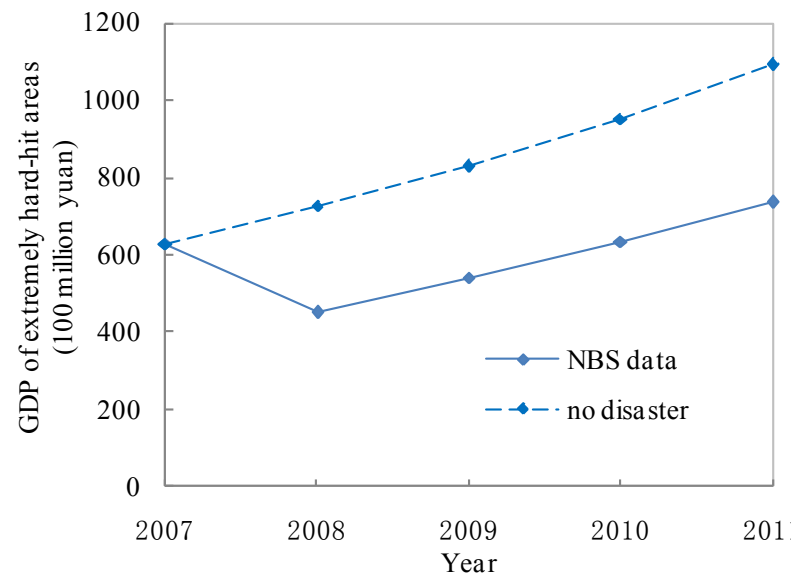

(a)

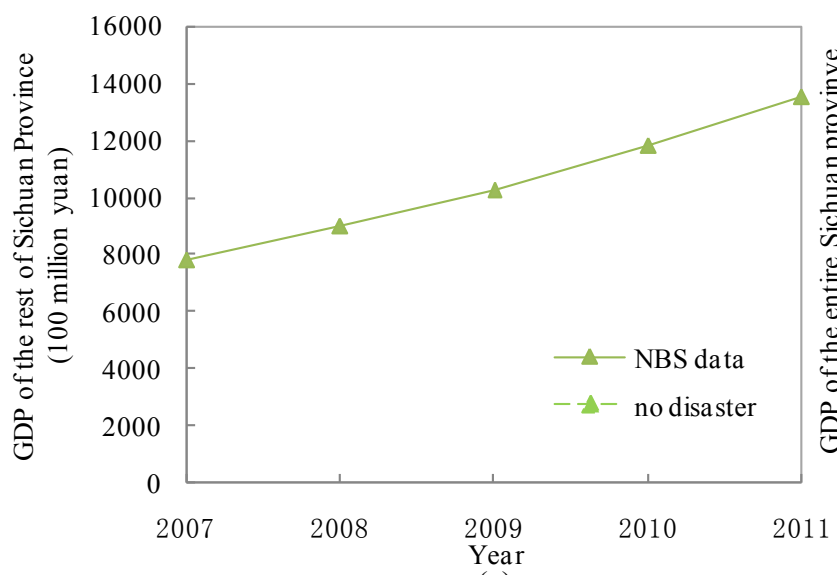

(c)

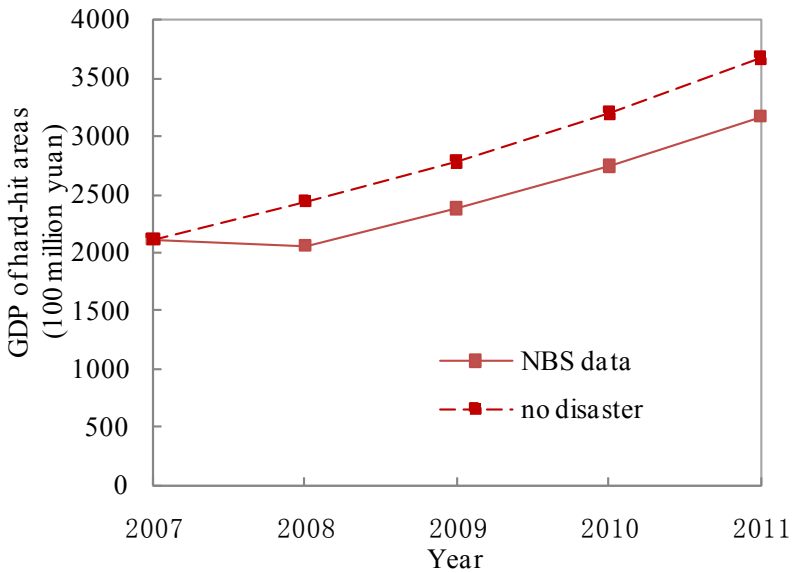

(b)

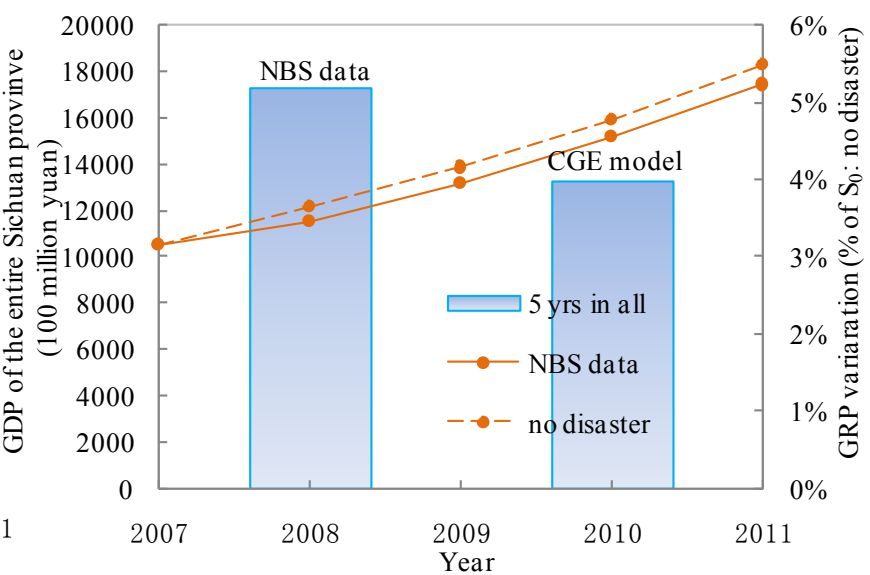

(d)

Fig. 7. Variations in Sichuan GDP, in percent of $S_{0}$ (no-disaster scenario) GDP based on NBS data and the CGE model.

\section{Conclusions and discussion}

In this study, a popular regional economic impact assessment tool, i.e., the CGE model, was improved by incorporating the positive effects of reconstruction. During the reconstruction period from 2008 to 2011 for the Wenchuan Earthquake, which hit China in 2008, under the reconstruction scenario $\left(S_{1}\right)$, the GDP loss incurred by Sichuan is 283.5 billion Yuan, and the annual average loss is 70.89 billion Yuan, which represents $10 \%$ of the direct economic loss. Under the non-reconstruction scenario $\left(S_{2}\right)$, the GDP loss incurred by Sichuan is 425.00 billion Yuan, and the annual average loss is 106.25 billion Yuan, which represents $15 \%$ of the direct economic loss. It can be concluded that the assessment ignoring the reconstruction effects in the wake of natural hazards usually overestimates the GDP loss. In the year when reconstruction is concluded, the gap in economic growth between the reconstruction and non-disaster scenarios is reduced to $3 \%$, a level that should take another four years to achieve under the non-reconstruction scenario. Therefore, in the case of the Wenchuan Earthquake, reconstruction reduces the recovery period by four years.

If we model post-disaster economic growth trends on a quarterly, monthly or weekly basis, we can model the shortterm characteristics of a given disaster (Dixon et al., 2010). In addition, the long-term sustainable development after disasters is worth noting. Further studies may focus on constructing hybrid models (intermediate between econometric models and CGE or IO models) to reflect the short and long (5-year or 10-year period) characters of disaster impact. From a spatial perspective, the disaster economic effects also extend to other areas besides the disaster-affected area through financial and goods flow. Constructing a model that can assess the social and economic impacts on multiple areas surrounding disaster areas is essential for developing a comprehensive database of social and economic assessment models for natural disasters.

Acknowledgements. This research was supported by the National Basic Research Program of China (no. 2012CB955402) and the National Natural Science Foundation of China (no. 41171401; 
no. 41101506). Thanks to three referees and the editor for constructive comments. The views expressed in this paper are those of the authors and do not necessarily represent the positions of Beijing Normal University. The authors are solely responsible for any errors and omissions.

Edited by: T. Glade

Reviewed by: J. He, A. Rose, and one anonymous referee

\section{References}

Christensen, L. R. and Jorgenson, D. W.: US income, saving, and wealth, 1929-1969, Rev. Income Wealth, 4, 329-362, 1973.

Dixon, P. B. and Maureen, R.: Dynamic General Equilibrium Modeling for Forecasting \& Policy: a Practical Guide \& Documentation of MONASH, North Holland, 2002.

Dixon, P. B., Lee, B., Muehlenbeck, T., Rimmer, M. T., Rose, A., and Verikios, G.: Effects on the U.S. of an H1N1 epidemic: Analysis with a quarterly CGE model, Journal of Homeland Security and Emergency Management, p. 751, 2010.

DRC (Development Research Center of the State Council): Social Accounting Matrix China, available at: http://www.drcnet.com. $\mathrm{cn} /$ temp/20051228/hsjz/english\%20version/index.html, cited 1 SepTEMBER 2012, updated 2000.

ECLAC (Economic Commission for Latin America and the Caribbean): Handbook for estimating the socio-economic and environmental effects of disaster, Santiago, Chile, 2003.

FEMA (Federal Emergency Management Agency): Hazus ${ }^{\circledR}-\mathrm{MH}$ MR5 Technical Manuals and User's Manuals, Washington, DC, 2011

Goldsmith, R. W.: A perpetual inventory of national wealth, Studies in Income and Wealth, 14, 50-61, 1951.

Government of Japan: Road to recovery, available from http://www. kantei.go.jp/foreign/incident/road_to_recovery.html, last access 11 March 2013, updated Mar 2012.

Greenberg, M. R., Lahr, M., and Mantell, N.: Understanding the economic costs and benefits of catastrophes and their aftermath: A review and suggestions for the U.S. federal government, Risk Analysis, 1, 83-96, 2007.

Greenberg, M., Haas, C., Cox, A., Lowrie, K., McComas, K., and North, W.: Ten most important accomplishments in risk analysis, 1980-2010, Risk Analysis, 5, 771-781, 2012.

Haimes, Y. Y., Horowitz, B. M., Lambert, J. H., Santos, J. R., Lian, C. Y., and Crowther, K. G.: Inoperability input-output model for interdependent infrastructure sectors. I: Theory and methodology, J. Infrastruct. Syst., 2, 67-79, 2005a.

Haimes, Y. Y., Horowitz, B. M., Lambert, J. H., Santos, J., Crowther, K., and Lian, C. Y.: Inoperability input-output model for interdependent infrastructure sectors. II: Case studies, J. Infrastruct. Syst., 2, 80-92, 2005b.

Hallegatte, S.: An adaptive regional input-output model and its application to the assessment of the economic cost of Katrina, Risk Analysis, 3, 779-799, 2008.

Horridge, M., Madden, J., and Wittwer, G.: The impact of the 2002 2003 drought on Australia, J. Policy Model., 3, 285-308, 2005.

IPCC: Managing the risks of extreme events and disasters to advance climate change adaptation, in: Special report of the intergovernmental panel on climate change (IPCC), edited by: Field, C. B., Barros, V., Stocker, T. F., Qin, D., Dokken, D., Ebi, K. L.,
Mastrandrea, M. D., Mach, K. J., Plattner, G.-K., Allen, S. K., Tignor, M., and Midgley, P. M., United Kingdom and New York, NY, USA, 582 pp., 2012.

Jung, J., Santos, J. R., and Haimes, Y. Y.: International trade inoperability input-output model (IT-IIM): Theory and application, Risk Analysis, 1, 137-154, 2009.

Kates, R. W., Colten, C. E., Laska, S., and Leatherman, S. P.: Reconstruction of New Orleans after Hurricane Katrina: A research perspective, Proceedings of the National Academy of Sciences of the United States of America, 40, 14653-14660, 2006.

Liao, M. Q. and Ma, X. D.: A research of the second-stage inputoutput analytic method and its application, Statist. Res., 2, 96100, 2009.

Miller, R. E. and Blair, P. D.: Input-output analysis: foundations and extensions, 2nd Edn., Cambridge University Press, New York, 1985.

NCDR (National Commission for Disaster Reduction), MOST (Ministry of Science and Technology of China): Wenchuan earthquake disaster: a comprehensive analysis and evaluation, Science Press, Beijing, 2008.

NDRC (National Development and Reform Committee of China): The state overall planning for the post-Wenchuan earthquake restoration and reconstruction, available at: http://en.ndrc.gov. cn/policyrelease/P020081010622006749250.pdf (last access: 17 October 2009), 2008.

Okuyama, Y.: Modeling spatial economic impacts of an earthquake: Input-output approaches, Disast. Prevent. Manage., 4, 297-306, 2004.

Okuyama, Y.: Economic modeling for disaster impact analysis: past, present, and future, Econ. Syst. Res., 2, 115-124, 2007.

Oladosu, G.: A non-market computable general equilibrium model for economic analysis and climate change in the Susquehanna river basin, Pennsylvania State University, 2000

Pauw, K., Thurlow, J., Bachu, M., and Van Seventer, D. E.: The economic costs of extreme weather events: A hydrometeorological CGE analysis for Malawi, Environ. Develop. Econom., 2, 177198, 2011.

Przyluski, V. and Hallegatte, S.: Indirect costs of natural hazards, in: CONHAZ report WP02 2 supported by the European Community's Seventh Framework Program through the grant to the budget of the Coordination Action CONHAZ, Contract 244159, SMASH-CIRED, France, 41 pp., 2011.

Rose, A.: Economic resilience to natural and man-made disasters: Multidisciplinary origins and contextual dimensions, Environ. Haz., 7, 383-398, 2007.

Rose, A. and Liao, S.: Modeling regional economic resilience to disasters: A computable general equilibrium analysis of water service disruptions, J. Region. Sci., 1, 75-112, 2005.

Rose, A., Oladosu, G., and Liao, S.: Business interruption impacts of a terrorist attack on the electric power system of Los Angeles: customer resilience to a total blackout, Risk Analysis, 3, 513531, 2007.

Santos, J. R., May, L., and Haimar, A. E.: Risk-Based input-output analysis of influenza epidemic consequences on interdependent workforce sectors, Risk Analysis, 9, 1620-1635, 2013.

SCIO (The State Council Information Office of the People's Republic of China): Recovery \& reconstruction data indicators for Wenchuan earthquake, available from: http: 
//www.scio.gov.cn/xwfbh/xwbfbh/wqfbh/2011/0510/index.htm, cited 12 March 2013, updated May 2011.

Shi, P. J., Jaeger, C., and Ye, Q.: Integrated risk governance: science plan and case studies of large-scale disasters, Springer, Berlin, 2013.

Shi, P. J.: On the role of government in integrated disaster risk governance: Based on practices in China, International Journal of Disaster Risk Science, 3, 139-146, 2012.

Sichuan Bureau of Statistics: Sichuan statistical yearbook 2012, China Statistics Press, Beijing, 2012.

Sue Wing, I.: ARkStorm computable general equilibrium model documentation, Boston University, Boston, MA, 2010.

Tatano, H. and Tsuchiya, S.: A framework for economic loss estimation due to seismic transportation network disruption: a spatial computable general equilibrium approach, Natural Haz., 2, 253-265, 2008.

Tirasirichai, C. and Enke, D.: Case study: Applying a regional CGE model for estimation of indirect economic losses due to damaged highway bridges, The Engineering Economist, 4, 367-401, 2007.

Vennemo, H., Aunan, K., He, J. W., Hu, T., and Li, S. T.: Benefits and costs to China of three different climate treaties, Res. Energ. Econom., 3, 139-160, 2009.
Wittwer, G. and Griffith, M.: Modeling drought and recovery in the southern Murray-Darling basin, Austr. J. Agr. Res. Econom., 3, 342-359, 2011.

Wu, J. D., Li, N., Hallegatte, S., Shi, P. J., Hu, A. J., and Liu, X. Q.: Regional indirect economic impact evaluation of the 2008 Wenchuan earthquake, Environ. Earth Sci., 1, 161-172, 2012.

Xie, W., Li, N., Wu, J.-D., and Liu, X.-Q.: Evaluation of indirect loss from hypothetical catastrophes in two regions with different economic development levels in China, Nat. Hazards Earth Syst Sci., 12, 3325-3335, doi:10.5194/nhess-12-3325-2012, 2012.

Xie, W., Li, N., Hu, A. J., Gao, Y., Ji, and Z. H.: Assessing the economic impact of environment disaster: a computable general equilibrium analysis, China Population, Res. Environ., 11, 2631,2012

Xie, W., Li, N., Yang, J., Ji, Z. H., Wu, J. D., Liu, X. Q., and Zhang, P.: On disaster insurance system from a disaster risk science perspective, J. Beijing Normal Univers. (Natural Science), 4, 406410, 2012.

Zhang, J., Wu, G. Y., and Zhang, J. P.: The estimation of China's provincial capital stock: 1952-2000, Econom. Res. J., 10, 3544, 2004 


\section{Appendix A}

\section{Traditional CGE model}

The traditional CGE model (please refer to Dixon and Maureen, 2002) usually includes several sectors. The essential productive factors entail capital and labor. The accounts of institutions involve residents, companies, governments, and trading. The government accounts are distinguished between the central government and local governments, while the trading accounts are differentiated among local, the rest of the country and the rest of the world. The dynamic version of the CGE model is a recursive dynamic model, which means that the current capital amount is composed of the capital stock, depreciation excluded, plus investments in the previous period. The traditional CGE model is composed of a production block, trade block, demand block, market clearing block and macro closure block. The structure of the standard CGE model is depicted in Fig. 2 (the part that is out of the box). With the aid of this framework, we will elaborate on the essential features of the CGE model.

\section{A1 Production block}

Every sector adopts the technology of constant returns to scale and makes decisions based on the principle of cost minimization. The production process is described by the fourtier, nested constant elasticity of substitution (CES) production function. The multiple tiers allow for the use of different substitution elasticities for different pairs of inputs. In addition, it is considered that there are intermediate input substitution possibilities for the energy sources, such as electricity, oil, etc. On the first tier, according to the CES production function, the gross output (XP) is determined by the capital, energy, labor aggregate (KEL) and other intermediate inputs (ND) (Eq. A1). On the second tier, the capital, energy, and labor aggregate (KEL) is disaggregated into labor (LD) and a capital and energy aggregate (KE) (Eq. A2). On the same tier, the non-energy intermediate inputs are disassembled by the Leontief structure into the need for various non-energy products $\left(\mathrm{XAp}^{\mathrm{nf}}\right)(\mathrm{Eq} . \mathrm{A} 3)$; in other words, there is no substitution possibility among them. On the third tier, the capital and energy aggregate (KE) is further divided into energy $(E)$ and capital (KD) based on the CES structure (Eq. A4). On the fourth tier, the energy aggregate is further disaggregated into different types of energy inputs, such as electricity, gas, coal and oil $\left(\mathrm{XAp}^{\mathrm{e}}\right)$ (Eq. A5).

$\mathrm{XP}_{i}=A_{i}^{\mathrm{xp}}\left[\alpha_{i}^{\mathrm{nd}}\left(\lambda_{i}^{n d} N D_{i}\right)^{\rho_{i}^{\mathrm{xp}}}+\alpha_{i}^{\mathrm{kel}}\left(\lambda_{i}^{\mathrm{kel}} \mathrm{KEL}_{i}\right)^{\rho_{i}^{\mathrm{xp}}}\right]^{\frac{1}{\rho_{i}^{\mathrm{xp}}}}$

$\mathrm{KEL}_{i}=A_{i}^{\mathrm{kel}}\left[\alpha_{i}^{\mathrm{ke}}\left(\lambda_{i}^{\mathrm{ke}} \mathrm{KE}_{i}\right)^{\rho_{i}^{\mathrm{kel}}}+\alpha_{i}^{l}\left(\lambda_{i}^{l} \mathrm{LD}_{i}\right)^{\rho_{i}^{\mathrm{kel}}}\right]^{\frac{1}{\rho_{i}^{\mathrm{kel}}}}$

$$
\mathrm{ND}_{i}=\min \left\{\lambda_{i}^{\mathrm{xapnf}} \mathrm{XAp}_{i}^{\mathrm{nf}} / \alpha_{i}^{\mathrm{xapnf}}\right\}
$$

$\mathrm{KE}_{i}=A_{i}^{\mathrm{ke}}\left[\alpha_{i}^{k}\left(\lambda_{i}^{k} \mathrm{KD}_{i}\right)^{\rho_{i}^{\mathrm{ke}}}+\alpha_{i}^{\mathrm{e}}\left(\lambda_{i}^{\mathrm{e}} E_{i}\right)^{\rho_{i}^{\mathrm{ke}}}\right]^{\frac{1}{\rho_{i}^{\mathrm{ke}}}}$

$E_{i}=A_{i}^{\mathrm{e}} \sum_{\mathrm{e}}\left(\alpha_{i}^{\mathrm{xape}}\left(\lambda_{i}^{\mathrm{xape}} \mathrm{XAp}_{i}^{\mathrm{e}}\right)^{\rho_{i}^{\mathrm{e}}}\right)^{\frac{1}{\rho_{i}^{\mathrm{e}}}}$

where $A$ is the transfer parameter, $\lambda$ is the efficiency parameter corresponding to each input, $\alpha$ is the share parameter, $\rho=\sigma-1 / \sigma$, and $\sigma$ is the elasticity of the substitution production function of the two inputs. The lower-case superscripts represent different tiers of the production process and correspond to different parameter values, and the lower-case subscripts $i$ represent different industrial sectors.

During the production process, in addition to the aforementioned input, the central government as well as the local government will levy various production taxes (Eq. A6).

$\mathrm{PP}_{i}=\mathrm{PX}_{i}\left(1+\mathrm{tpc}_{i}+\operatorname{tpr}_{i}\right)$

where PX represents the unit cost of the product without tax, $\mathrm{PP}$ represents the cost including tax, and tpc and tpr represent the production tax rates levied by the central government and local government, respectively.

\section{A2 Trade block}

The company describes the sales of the products with the two-tier nested constant elasticity of transformation (CET) function. In the first tier, the company chooses the optimal combination of domestic sale and export sale (Eq. A7) that maximizes revenues. In the second tier, the domestic sale is divided according to the CET function into local sales and the rest of the country (Eq. A8).

In terms of the sources of the products, the model adopts the Armington hypothesis, that is, the products within or outside the region are assumed to be of different qualities so that they cannot serve as substitutions for each other. Here, they are represented by the two-tier nested CES function. In the first tier, consumers from different regions select the optimal combination of domestic products and import products that minimize costs (Eq. A9). In the second tier, the demand for domestic products is divided, according to the CET function, into the demand for products from local areas and that for products from other areas in the country (Eq. A10).

This model uses the assumption of "small country"; that is, the imports, exports and transfer of the local products will not affect other areas in the country or the international market. The model includes tariff and export rebate; that is, it is 
considered that there are discrepancies between the international and domestic prices of the products.

$$
\begin{aligned}
& \mathrm{XP}_{i}=\left[\alpha_{i}^{d}\left(\mathrm{XD}_{i}\right)^{\frac{\sigma_{i}+1}{\sigma_{i}}}+\alpha_{i}^{e}\left(\mathrm{ES}_{i}\right)^{\frac{\sigma_{i}+1}{\sigma_{i}}}\right]^{\frac{\sigma_{i}}{\sigma_{i}+1}} \\
& \mathrm{XD}_{i}=\left[\alpha_{i}^{\mathrm{dd}}\left(\mathrm{XDD}_{i}\right)^{\frac{\sigma_{\mathrm{xd}, i}+1}{\sigma_{\mathrm{xd}, i}}}+\alpha_{i}^{\mathrm{de}}\left(\mathrm{XDE}_{i}\right)^{\frac{\sigma_{\mathrm{xd}, i}+1}{\sigma_{\mathrm{xd}, i}}}\right]^{\frac{\sigma_{\mathrm{xd}, i}}{\sigma_{\mathrm{xd}, i}+1}} \\
& \mathrm{XA}_{i}=\left[\alpha_{i}^{\mathrm{da}}\left(\mathrm{XDA}_{i}\right)^{\frac{\omega_{i}-1}{\omega_{i}}}+\alpha_{i}^{m}\left(\mathrm{XM}_{i}\right)^{\frac{\omega_{i}-1}{\omega_{i}}}\right]^{\frac{\omega_{i}}{\omega_{i}-1}} \\
& \mathrm{XDA}_{i}=\left[\alpha_{i}^{\mathrm{dd}}\left(\mathrm{XDD}_{i}\right)^{\frac{\omega_{\mathrm{xda}, i}-1}{\omega_{\mathrm{xda}, i}}}+\alpha_{i}^{\mathrm{dm}}\left(\mathrm{XDM}_{i}\right)^{\frac{\omega_{\mathrm{xda}, i}-1}{\omega_{\mathrm{xda}, i}}}\right]^{\frac{\omega_{\mathrm{xda}, i}}{\omega_{\mathrm{xda}, i}-1}}
\end{aligned}
$$

\section{A3 Demand block}

Residents' incomes come from the labor supply and transfer payments from enterprises. The disposable incomes of residents are composed of the incomes after deducting personal income tax and the transfer payments of the local government. One part of the disposable incomes is saved at a fixed deposit rate, and the rest of the incomes are all spent on commodities and services. Residents choose the optimal combinations of commodities within budget constraints that maximize utility. The corporate revenues come from the return on capital employed and transfer to the residents after deducting corporate income tax. The central government revenues are derived from the production tax, personal income tax, corporation income tax, tariff, and transfer payments from local governments, while the local government's revenues stem from the production tax, personal income tax, corporation income tax, and transfer payments from the central government. The consumptive quantity of the commodities and services by the central and local governments is exogenously fixed.

\section{A4 Market clearing and macro closure block}

The standard CGE model contains three types of balances in commodity markets: the balances between supply and demand of commodities and services in the local markets (Eq. A11), in the international markets and in the interprovincial markets. Due to the similar notation of supply and demand in the latter two markets, their market clearing equations will not be displayed.

$$
\mathrm{XA}_{i}=\sum_{j} \mathrm{XAp}_{i, j}+\mathrm{QH}_{i}+\mathrm{QLC}_{i}+\mathrm{QGC}_{i}+\mathrm{QINV}_{i}
$$

The traditional CGE model features the following balance: demand/supply factor balance; investment/savings balance; central and local government accounting balance; and external balance. There are different closures in every balance. For the disaster-specific closures in each balance, see Sect. 3.2.

\section{A5 Dynamic block}

The dynamic feature of the model derives from the accumulation of capital. The current capital amount (KStock) is composed of the capital stock in the previous period (KStock $\mathrm{K}_{-1}$ ), depreciation excluded ( $\delta$ is depreciation rate), plus the fixed capital formation $\left(\mathrm{XC}_{\mathrm{Inv},-1}\right)$ in the previous period (Eq. A12).

$\mathrm{KStock}_{i}=\left(1-\delta_{i}\right) \mathrm{KStock}_{i,-1}+\mathrm{XC}_{\mathrm{i}, \text { Inv },-1}$

Labor supply and technology parameters are given exogenously. 